\title{
Intermodalität - auch in der FVT
}

Liebe Leserin, lieber Leser,

die VDI-Gesellschaft Fahrzeug- und Verkehrstechnik bietet mit ihren Fachbereichen eine Plattform, die sich wie wenige andere dazu eignet, das Thema Mobilität in allen seinen Facetten zu betrachten. Denn obwohl die Autobranche dort ein hohes Gewicht hat, finden auch die Bahntechniker, die Luft- und Raumfahrtingenieure und die Schiffbauer eine fachliche Heimat im VDI, und alle gemeinsam kommen im Fachbereich „Verkehr und Umfeld“ auch mit Stadtund Verkehrsplanern zusammen. Dieser Fachbereich hat sich kürzlich neu konstituiert, und seine ersten Arbeiten bilden mit zahlreichen Beiträgen das Herzstück unseres Sonderhefts.

Das Thema lag 2015 im Trend und somit befasste sich auch der Automotive Summit des Dachverbands der Automobilingenieursvereine FISITA mit „Personal Mobility“ und zeigte auf, dass darin eine echte Herausforderung für die Automobilindustrie liegt - weniger für die Ingenieure als für das Management. Die Herausforderer, und diese Feststellung wird von vielen Beobachtern geteilt, sitzen im Silicon Valley. Allerdings sind es nicht so sehr die Prototypen und Serienfahrzeuge, die dort entstehen, mit denen sich die Autoindustrie befassen sollte, sondern die sich abzeichnenden Veränderungen in den Geschäftsmodellen und den Wertschöpfungsketten.

Zu guter Letzt waren es 2015 auch bei traditionellen, automobiltechnischen Themen der FVT die Nicht-Autofahrer, die die Aufmerksamkeit auf sich ziehen. Denn nachdem die Autoinsassen dank der ständigen Weiterentwicklung der Fahrzeuge immer besser geschützt sind, richtet sich der Blick immer stärker auf
Verkehrsteilnehmer, die zu Fuß oder auf zwei Rädern verunglücken. Dazu haben wir ein ausführliches Interview mit dem FVT-Vorsitzenden Professor Rodolfo Schöneburg im Heft.

Wir wünschen Ihnen viel Vergnügen bei der Lektüre unseres Sonderhefts und ein sicheres Fortkommen bis zum nächsten Jahr - mit welchem Verkehrsmittel auch immer.

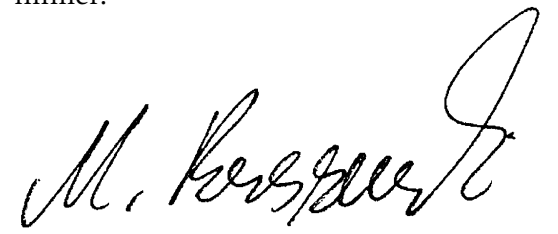

Markus Bereszewski, Leitender Redakteur Sonderprojekte und internationale Medien

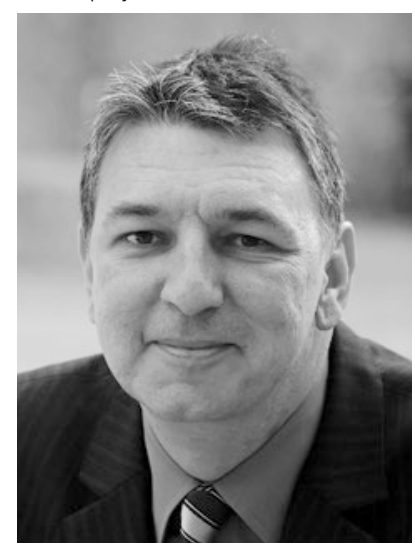

